\title{
EFEITO DA DENSIDADE DE POPULAÇÃO SOBRE OS TEORES DE ÁCIDO ASCÓRBICO E CARBOIDRATOS SOLÚVEIS DE BERINJELA (Solanum melongena)*
}

\author{
LUIZ EdUARDO GUTIERREZ ** \\ KEIGO MINAMI *** \\ TÂNIA P. CaMargo $* * * *$ \\ WALDIR MANTOVANI $* * * *$
}

\section{RESUMO}

Amostras de berinjela (Solanum melongena) de densidades de 11.111 a 31.746 plantas/ha foram analisadas quanto aos teores de matéria seca, ácido ascórbico, carboidratos solúveis totais, sacarose, glucose e frutose. Com exceção da matéria seca, não foram detectadas diferenças significativas entre os teores dos constituintes analisados em função das diversas densidades de plantas. Os frutos obtidos de maiores densidades de plantas apresentaram maior teor de matéria seca. O teor de ácido ascórbico variou de 5,9 a 10,6 $\mathrm{mg} / 100 \mathrm{~g}$ peso fresco. Os teores de carboidratos solúveis, expressos $\mathrm{cm} \mathrm{g} / 100 \mathrm{~g}$ peso fresco, foram os seguintes: sacarose, $(0,13-0,22)$, glucose $(0,91-1,37)$ e frutose $(0,83-1,11)$.

\section{INTRODUÇÃO}

A beringela em nosso Estado é uma hortaliça muito pouco consumida, visto que segundo dados do Instituto de Economia Agrícola, as hortaliças mais comercializadas no Estado de São Paulo em 1975 foram, pela ordem, tomate, batata, cebola, repolho, cenoura, chuchu, alface, pepino, vagem e abobrinha. Talvez este fato possivelmente, explique as poucas referências encontradas sobre esta hortaliça.

O teor de ácido ascórbico em beringela é muito baixo como mostraram dados apresentados por MORTENSEN \& BULLARD (1971).

\footnotetext{
* Entregue para publicação em: 24/9/1976

* Departamento de Química, E.S.A. "Luiz de Queiroz"

** Departamento de Agricultura e Horticultura, ESALQ

*** Estagiária junto ao Depto. de Agricultura e Horticultura da E.S.A. "Luiz de Queiroz".
} 
O teor de carboidratos solúveis totais gira em torno de $3,3 \%$ (MORTENSEN \& BULLARD, 1971) e que nesta fração os principais componentes foram glucose e frutose, encontrados em igual proporção (SHALLENBERGER, 1970; WALI \& HASSAN, 1965).

E fato conhecido que o organismo animal apresenta diferentes comportamentos em relação aos tipos de carboidratos da dieta. BROOK \& NOEL (1969) relataram que o fornecimento de frutose pode incrementar a deposição de gordura corporal.

Segundo SINGH et alii (1974) a berinjela é um dos vegetais mais cultivados na India, relatando para diversas variedades que os açúcares não-redutores foram detectados em maior proporção.

O teor de ácido ascórbico da berinjela pode ser afetado por diversos fatores, como por exemplo, quantidade de fertilizantes (ONANAKUMARI \& SATYANARAYANA, 1971), ação de TMTD (FEL'DMAN \& KOBELEVA, 1970) e variedades (SINGH et alii, 1974).

O objetivo do presente trabalho foi verificar o efeito da densidade de plantas sobre a composição da berinjela em relação aos teores de ácido ascórbico e carboidratos solúveis e identificar os açúcares presentes na fração carboidratos solúveis totais.

\section{MATERIAL E MÉTODOS}

Amostras de berinjela (Solanum melongena) cv. Florida Market foram analisadas quanto aos teores de matéria seca, ácido ascórbico, carboidratos solúveis totais, sacarose, glucose e frutose com o objetivo de verificar o efeito da densidade de plantas.

As densidades de plantas utilizadas foram as seguintes:

\begin{tabular}{ccc}
\hline Tratamentos & Plantas/Hectare \\
\hline A & 11.111 \\
C & 12.345 \\
D) & 14.814 (retangular \\
E & 14.814 (quadrado) \\
F & 20.408 \\
\hline
\end{tabular}

O plantio foi efetuado em latossolo pertencente ao Departamento de Agricultura e Horticultura da ESALQ, tendo recebido uma adubação 
de $50 \mathrm{~g}$ por cova da fórmula 4-14-8, mais $5 \mathrm{~g}$ de $\mathrm{N}$ em cobertura por planta aos 25, 50 e 75dias após o transplante.

A matéria seca foi obtida por secagem das amostras em estufa a $100-105^{\circ} \mathrm{C}$ até peso constante.

O teor de ácido ascórbico foi determinado segundo técnica descrita em JACOBS (1958) e antes do preparo do extrato, os frutos tiveram a casca removida.

A extração de carboidratos solúveis foi realizada na amostra fresca, utilizando-se etanol $80 \%$ como extrator com aquecimento de 30 minutos. O teor foi obtido segundo método fenol-sulfúrico de DUBOIS et alii (1956).

Para a separação e identificação dos açúcares foi adotada a técnica de cromatografia de papel de filtro descrito por ARZOLLA \& FONSECA (1965). A quantificação foi realizada pelo método descrito por DUBOIS et alii (1956).

Para análise estatística foi utilizado um delineamento inteiramente casualizado com 3 repetições (PIMENTEL GOMES, 1970) e adotado o nível de $5 \%$ de significância para comparação das médias pelos testes F e Tukey.

\section{RESULTADOS E DISCUSSÃO}

Como pode ser observado nos resultados apresentados nos diversos QUADROS deste trabalho, apenas a matéria seca foi significativamente afetada pela densidade das plantas. Os frutos obtidos com um densidade de 31.746 plantas/ha apresentaram maior teor de matéria seca (QUADRO 1). Os resultados de matéria seca apresentados no QUADRO 1 estão de acordo com os citados por WALI \& HASSAN (1965).

Os teores de ácido ascórbico (QUADRO 2) não foram afetados significativamente pelo espaçamento, embora o tratamento $\mathbf{F}$ apresentasse teores mais elevados. Os valores contidos no QUADRO 2 foram inferiores aos apresentados por SINGH et alii (1974) e de acordo com os dados citados por MORTENSEN \& BULLARD (1971). As diferenças encontradas entre dados citados na Literatura com os valores do QUADRO 2 poderiam ser explicados pelas variedades utilizadas (SINGH et alii, 1974) e nível de adubação, como foi observado por GNANAKUMARI \& SATYANARAYANA (1971) os maiores teores de ácido ascórbico em beringela foram obtidos com doses de $224-280 \mathrm{~kg}$ de fertilizantes por hectare.

Os principais açúcares livres presentes nas amostras de berinjela foram glucose e frutose: na proporção aproximada de 1:1. 
Os teores de glucose e frutose (QUADRO 5 e 6 ) situaram-se em torno de $1 \mathrm{~g} / 100 \mathrm{~g}$ peso fresco, resultados que confirmam dados de SHALLENBERGER (1970) e WALI \& HASSAN (1965).

Os teores de sacarose citados no QUADRO 4 foram bastante baixos $(0,12$ a $0,33 \mathrm{~g} / 100 \mathrm{~g}$ peso fresco), esndo que o mesmo fenômeno foi observado por WALI \& HASSAN (1965) quando detectaram traços de sacarose para a variedade violeta ROMI, tendo assinalado maiores teores desse açúcar na berinjela branca.

Carboidratos solúveis totais (QUADRO 3) variaram de 2,00 a 3,08 $\mathrm{g} / 100 \mathrm{~g}$ peso fresco e foram inferiores aos apresentados por MORTENSEN \& BULLARD (1971) e estão de acordo com resultados de SINGH et alii (1974) para diversas variedades cultivadas na India.

A fração carboidratos solúveis totais de berinjela apresentou mais de $80 \%$ do seu teor constituído por glucose, frutose e sacarose (QUADRO $7)$, sendo que o tratamento A apresentou a mais alta percentagem $(99,3 \%)$.

\section{CONCLUSÕES}

A partir dos resultados obtidos, as seguintes conclusões podem ser apresentadas:

1. A densidade das plantas não afetou significativamente os teores de ácido ascórbico e carboidratos solúveis. Apenas a matéria seca foi afetada.

2. Os principais açúcares da fração carboidratos foram glucose e frutose em menor teor a sacarose.

QUADRO 1 - Matéria seca de amostras de beringela de diversas densidades de plantas (média de 3 repetições).

\begin{tabular}{ll}
\hline Tratamentos (plantas/ha) & $\%$ M.S. \\
\hline \hline A (11.111) & $=6,61 \mathrm{~b}$ \\
B (12.345) & $7,07 \mathrm{ab}$ \\
C (14.814 - retangular) & $7,15 \mathrm{ab}$ \\
D (14.814 - quadrado) & $6,77 \mathrm{~b}$ \\
E (20.408) & $7,68 \mathrm{ab}$ \\
F (31.746) & $8,27 \mathrm{a}$ \\
\hline
\end{tabular}

C.V. $=6,69 \%$

a, b: na coluna, médias seguidas de letras diferentes, diferem significativamente ao nível de $5 \%$ de probabilidade. 
QUADRO 2 - Teores de ácido ascórbico de amostras de berinjela obtirlas de diversas densidades de plantas (médias de 3 repetições).

\begin{tabular}{ccc} 
Tratamentos (plantas/ha) & $\%$ M.S. & g/100 g peso fresco \\
\hline \hline A (11.111) & 0,12 & 7,9 \\
B (12.345) & 0,14 & 10,5 \\
C (14.814 - retangular) & 0,09 & 6,4 \\
D (14.814 - quadrado) & 0,09 & 6,5 \\
E (20.408) & 0,07 & 5,9 \\
F (31.746) & 0,12 & 10,6 \\
\hline
\end{tabular}

C.V. $=22,16 \% \quad \mathrm{~F}$ não significativo

QUADRO 3 - Teores de carboidratos solúveis totais de amostras de berinjela obtidas de diversas densidades de plantas (médias de 3 repetições).

\begin{tabular}{ccc}
\hline Tratamentos (plantas/ha) & \% M.S. & $\mathrm{g} / 100 \mathrm{~g}$ peso fresco \\
\hline \hline A (11.111) & 35,14 & 2,32 \\
B (12.345) & 33,10 & 2,33 \\
C (14.814 - retangular) & 32,88 & 2,35 \\
D (14.814 - quadrado) & 31,13 & 2,12 \\
E (20.408) & 32,01 & 2,46 \\
F (31.746) & 37,10 & 3,08 \\
\hline
\end{tabular}

C.V. $=6,97 \% \quad$ F não significativo

QUADRO 4 - Teores de sacarose de amostras de berinjela obtidas de diversas densidades de plantas (médias de 3 repetições).

\begin{tabular}{ccc}
\hline Tratamentos (plantas/ha) & $\%$ M.S. & $\mathrm{g} / 100 \mathrm{~g}$ peso fresco \\
\hline \hline A (11.111) & 2,68 & 0,17 \\
B (12.345) & 3,04 & 0,21 \\
C (14.814 - retangular) & 1,92 & 0,13 \\
D (14.814 - quadrado) & 3,13 & 0,21 \\
E (20.408) & 1,95 & 0,15 \\
F (31.746) & 2,71 & 0,22 \\
\hline
\end{tabular}

C.V. $=31,59 \% \quad$ F não significativo


QUADRO 5 - Teores de glucose de amostras de berinjela obtidas de diversas densidades de plantas (médias de 3 repetições).

\begin{tabular}{ccc}
\hline Tratamentos (plantas/ha) & $\%$ M.S. & g/100 g peso fresco \\
\hline A (11.111) & 16,06 & 1,06 \\
B (12.345) & 13,62 & 0,96 \\
C (14.814 - retangular) & 12,79 & 0,91 \\
D (14.814 - quadrado) & 14,58 & 0,98 \\
E (20.408) & 14,39 & 1,10 \\
F (31.746) & 16,55 & 1,37
\end{tabular}

$\mathrm{C} . \mathrm{V} .=13,37 \% \quad \mathrm{~F}$ não significativo

QUADRO 6 - Teores de frutose de amostras de berinjela obtidas de diversas densidades de plantas (médias de 3 repetições).

\begin{tabular}{ccc} 
Tratamentos (plantas/ha) & \% M.S. & g/100 g peso fresco \\
\hline A (11.111) & 16,17 & 1,07 \\
B (12.345) & 13,98 & 0,99 \\
C (14.814 - retangular) & 14,65 & 1,05 \\
D (14.814 - quadrado) & 12,36 & 0,83 \\
E (20.408) & 12,08 & 0,90 \\
F (31.746) & 13,57 & 1,11 \\
\hline
\end{tabular}

C.V. $=13,13 \% \quad \mathrm{~F}$ não significativo

QUADRO 7 - Carboidratos solúveis de berinjela, expresso em $\mathrm{g} / 100 \mathrm{~g}$ peso seco (média de 3 repetições).

\begin{tabular}{lrrrrrr}
\hline \multirow{2}{*}{ Carboidratos } & \multicolumn{7}{c}{ Tratamentos (*) } \\
\cline { 2 - 8 } & $\mathrm{A}$ & $\mathrm{B}$ & $\mathrm{C}$ & $\mathrm{D}$ & $\mathrm{E}$ & $\mathrm{F}$ \\
\hline \hline Solúveis Totais & 35,14 & 33,10 & 32,88 & 31,13 & 32,01 & 37,10 \\
Sacarose & 2,68 & 3,04 & 1,92 & 3,13 & 1,95 & 2,71 \\
Glucose & 16,06 & 13,62 & 12,79 & 14,58 & 14,39 & 16,55 \\
Frutose & 16,17 & 13,98 & 14,65 & 12,36 & 12,08 & 13,57 \\
Açúcares livres x 100 & & & & & & \\
\hline \multicolumn{1}{c}{ Totais } & 99,3 & 92,6 & 89,3 & 96,6 & 88,9 & 88,5 \\
\hline
\end{tabular}




\section{SUMMARY}

\section{EFFECT OF PLANT POPULATION DENSITY OVER ASCORBIC ACID AND SOLUBLE CARBOHYDRATES CONTENTS OF EGGPLANT (Solanum melongena)}

Eggplant (Solanum melongena) samples from 11.111 to 31.746 plants/ha densities were analysed in relation dry weight, ascorbic acid, total soluble carbohydrates, sucrose, glucose and fructose contents. Dry weight was affected statistically by plants density, the fruits from higher plant density showed highest level of dry meight. Other constituents were not affected by plant density. Ascorbic acid content varied from 5.9 to $10.6 \mathrm{mg} / 100 \mathrm{~g}$ on fresh weight basis. Soluble carbohydrate content, in $\mathrm{g} / 100 \mathrm{~g}$ dry weight basis, were: sucrose $(0.13-0.22)$, glucose $(0.91-1.37)$, total $(2.12-3.08)$ and fructose $(0.83-1.11)$.

\section{LITERATURA CITADA}

ARZOLLA, J.D.P. and H. FONSECA. 1965. Cromatografia de Açúcares Boletim Didático n. ${ }^{\circ}$ 7. E.S.A. "Luiz de Queiroz". 19 p.

BROOK, M. and P. NOEL. 1969. Influence of dietary liquid glucose, sucrose and fructose on body fat formation. Nature, 222: $562-563$.

DUBOIS, M., K.A. GILlES, J.K. HAMILTON, P.A. REBERS and F. SMITH. 1956. Colorimetric method for determination of sugars and related substances. Anal. Chem., $28: 350-356$.

FEL'DMAN, A.L. and S.M. KOBELEVA. 1970. The effect of TMTD on the nutritional value of potatoes, sweet peppers and eggplants. Himija sel.' Hoz., 8: 32-33. In: Horticultural Abstracts, 41: 177.

GNANAKUMARI and G. SATYANARAYANA. 1971. Effect of $N, \dot{P}$ and $K$ fertilizers at different rates on flowering, yield and composition of brinjal (Solanum melongena L.). Indian Journal of Agricultural Science, 41: 554-558. In: Horticultural Abstracts, 42 : 921.

JACOBS, M.B. 19584 The Chemical Analysis of Foods and Foods Products. Van Nostrand. New York. 971 p.

PIMENTEL GOMES, F. 1970. Curso de Estatística Experimental. 4. a ed. Livraria Nobel. São Paulo. 430 p.

SHALLENBERGER, R.S. 1970. Nutritional quality in fruits and vegetables. HortScience, 5: 100-101.

SINGH, R., J. SINGH and K.S. NANDPURI. 1974. Chemical evaluation of some promising varieties of brinjal (Solanum melongena L.). The Indian Journal of Horticulture, $31: 242-245$.

WALI, Y.A. and Y.M. HASSAN. 1965. Qualitative chromatography survey of the sugars prevailing in some horticultural crops. Proc. Amer. Soc. Hort. Sci., 87: 264-269. 
